\title{
El carácter laboral de la prostitución en la jurisprudencia constitucional peruana y colombiana*
}

\author{
The Labor Nature of Prostitution in Peruvian and Colombian Constitutional Jurisprudence
}

\author{
Luz Pacheco Zerga ${ }^{\text {a }}$ \\ Universidad de Piura, Perú \\ luz.pacheco@udep.edu.pe \\ ORCID: https://orcid.org/0000-0002-6794-9865
}

DOI: https://doi.org/10.11144/Javeriana.vj69.clpj

Recibido: 11 Febrero 2017

Aceptado: 23 Mayo 2017

Publicado: 30 Diciembre 2020

\section{Resumen:}

Desde hace algunas décadas, se propone en algunas instituciones - entre las que se cuenta la Corte Constitucional de Colombia - calificar el ejercicio de la prostitución como trabajo sexual, y otorgar a las denominadas trabajadoras sexuales los beneficios establecidos por el Derecho Laboral. La presente investigación, realizada desde la dogmática jurídica, se orienta a determinar si el ejercicio de la prostitución se entiende como trabajo; si merece el debido respeto a la dignidad humana, y si las Sentencias T-629 de 2010 y T-594 de 2016 de la Corte Constitucional de Colombia son deberían ser de obligatorio cumplimiento.

Palabras clave: dignidad humana, no discriminación, trabajo, prostitución, trabajo sexual, trabajadoras sexuales.

\section{Abstract:}

For some decades, it has been proposed in some legal means — among which the Constitutional Court of Colombia is counted - to classify the exercise of prostitution as sex work and to grant the so-called sex workers the benefits established by Labor Law. The present investigation, carried out from the legal dogmatic, is oriented to determine if the exercise of prostitution is assimilable to the concept work and respect due to human dignity and if sentences T-629-10 and T-594-16 of the Constitutional Court of Colombia should be mandatory.

Keywords: human dignity, nondiscrimination, work, prostitution, sex work, sex workers.

\section{Introducción}

La Corte Constitucional de Colombia, en las sentencias T-629-10 y T-594-16, ha calificado el ejercicio de la prostitución como trabajo sexual, y ha ordenado otorgar a las denominadas trabajadoras sexuales los beneficios establecidos por el Derecho Laboral. Perú y Colombia son miembros de la Comunidad Andina que, mediante la Decisión 545 del año 2003, otorgó un estatuto especial a los trabajadores migrantes de los países miembros ${ }^{1}$. Por lo tanto, la calificación jurídico-laboral realizada en Colombia podría originar problemas judiciales en Perú si un ciudadano colombiano que se dedica a la prostitución pretendiese exigir la cobertura que la Corte Constitucional colombiana ha establecido para ese oficio en el vecino país. Sin embargo, es necesario analizar con detalle las razones presentadas, no sólo para combatir la discriminación en cualquiera de sus formas, sino para afianzar la protección de la mujer y evitar cualquier forma de violencia contra ella, con el fin de concluir si es conforme con el respeto a la dignidad humana, una especial protección jurídico-social para el oficio de la prostitución.

Los argumentos que se esgrimen en diferentes foros, y que han sido recogidos por la Corte Constitucional colombiana, giran en torno a cuatro razones ${ }^{2}$ :

Notas de autor

\footnotetext{
${ }^{a}$ Autora de correspondencia. Correo electrónico: luz.pacheco@udep.edu.pe
} 
- Que la prostitución no es mencionada en la Constitución ni está tipificada como delito por el Código Penal, por lo que se constituye en una actividad lícita que puede ser calificada como trabajo, merecedora de protección constitucional y legal.

- Que la persona es libre de ejercer el oficio o actividad que considere más apropiada para el libre desarrollo de su personalidad, lo cual se fundamenta en la dignidad humana. Por lo que, si alguien decide ejercer el oficio de la prostitución, y no se le reconocen los derechos laborales cuando lo realiza en forma dependiente y remunerada, se vulneraría el principio de igualdad y el de no discriminación, así como el de dignidad humana.

- Que la discriminación social que sufren las prostitutas se origina en una moral que no debe influir en la decisión de los jueces, ya que estamos en una sociedad abierta, pluralista y no confesional.

- Que el derecho corresponde a la realidad, y ésta indica que hay un fuerte movimiento económico en torno a la prostitución, la cual el Estado debe canalizar mediante impuestos y otras medidas, tanto de protección social a quienes ejercen el oficio, como de control en las ganancias de los burdeles o similares.

Teniendo en cuenta que tanto en Perú como en Colombia los fallos de los tribunales constitucionales tienen el carácter de cosa juzgada, y que los criterios hermenéuticos que establecen son de obligatorio cumplimiento para los operadores jurídicos — por su rol privilegiado de intérprete autorizado de la Constitución ${ }^{3}$ —, resulta indispensable dilucidar si es posible pronunciarse sobre la corrección constitucional de una sentencia emitida por uno de esos tribunales antes de analizar la cuestión de fondo.

En consecuencia, la presente investigación se dividirá en cuatro apartados: 1) La corrección constitucional de los fallos de las cortes constitucionales; 2) el derecho fundamental al trabajo y su protección jurídica; 3) la prostitución, el principio de no discriminación y su regulación jurídica; y 4) el concepto de dignidad humana como fundamento del orden social.

\section{La corrección constitucional de las sentencias de las cortes constitucionales}

La Constitución, desde el punto de vista de la argumentación jurídica, es un conjunto de enunciados lingüísticos que son calificados como disposiciones normativas, que se convierten en normas al ser interpretadas por un Tribunal o Corte Constitucional ${ }^{4}$. Estas interpretaciones tienen un efecto cascada sobre los magistrados del poder judicial y todos los operadores jurídicos. A su vez, la interpretación constitucional no sólo convierte en normas a aquellas que están directamente estatuidas, es decir, a las recogidas en el texto constitucional, sino que es capaz de adscribir otras normas como resultado de esta labor ${ }^{5}$.

Las normas directamente estatuidas se definen como aquellas que fluyen directamente desde el texto constitucional - considerado como una unidad-, tomando en consideración los criterios literal y sistemático ${ }^{6}$. Estas normas, por lo general, tienen una estructura abierta e indeterminada, que exige ser concretada para que sus disposiciones puedan operar efectivamente. Son ejemplo de este carácter abierto el artículo primero de las constituciones de Perú ${ }^{7}$ y Colombia ${ }^{8}$, en los que es necesario delimitar qué se entiende por dignidad o por interés general. En cambio, un ejemplo de estructura cerrada la encontramos en el inciso $E$. del artículo segundo de la Constitución del Perú, que tiene una operatividad inmediata, al establecer que toda persona es considerada inocente mientras no se haya declarado judicialmente su responsabilidad, afirmación que no requiere de interpretación, sino de mera aplicación. Algo similar ocurre con el artículo once la Constitución de Colombia, cuando prohíbe la pena de muerte: el contenido del mandato se encuentra claramente delimitado y se aplica sin mediar interpretación.

En resumen, para la operatividad de las disposiciones normativas de la Constitución que sean de carácter abierto, es necesario concretar el mandato constitucional. Esa concreción crea una norma adscrita a la norma 
constitucional directamente estatuida ${ }^{9}$ cuando es realizada por un tribunal constitucional. Su naturaleza jurídica es la misma que la de la norma constitucional directamente estatuida ${ }^{10}$, por lo tanto, ambas imponen la vinculación jurídica.

Respecto al grado de obligatoriedad de estos pronunciamientos ${ }^{11}$, se debe tener en cuenta que toda interpretación de estos tribunales se convierte en una norma adscrita a la Constitución; en esa medida, estas son vinculantes, al igual que los precedentes ${ }^{12}$, aunque exista entre ellas una diferencia de tipo formal. La razón expresada por el tribunal peruano es que en el precedente vinculante ${ }^{13}$ "se ejerce un poder normativo general, extrayendo una norma a partir de un caso concreto" ${ }^{14}$, y en el resto de jurisprudencia corresponderá a los operadores jurídicos concretar el contenido normativo a partir de los enunciados prescriptivos contenidos en las sentencias ${ }^{15}$.

A la vez, por tratarse de interpretaciones realizadas por seres humanos - que son falibles-, algunas de ellas pueden ser formalmente constitucionales por seguir la normativa procedimental, pero no materialmente porque la interpretación realizada no es coherente con los demás preceptos de la Constitución. En estos casos, la fundamentación constitucional no es correcta, pues vulnera exigencias de justicia del texto constitucional ${ }^{16}$. Por eso, el carácter preceptivo de las normas adscritas materialmente inconstitucionales tiene al menos tres excepciones, que liberan de su obligatoriedad ${ }^{17}$ : a) Cuando contradice de manera manifiesta alguna exigencia de la justicia constitucionalizada, y no existe razón alguna para su constitucionalidad o, de haberla, es tan débil que es fácilmente refutada; b) si la norma adscrita es contraria a las exigencias de la justicia — positivadas en la Convención Americana sobre Derechos Humanos declaradas como tales por la Corte Interamericana de Derechos Humanos-, salvo que la decisión de esta sea manifiestamente contraria a dicha Convención; y c) cuando en un caso concreto un juez considere que es posible una interpretación distinta que proteja más y mejor un derecho fundamental en ese supuesto ${ }^{18}$.

Como conclusión de este primer apartado, se diría que no sólo se pueden, sino que se deben analizar las sentencias constitucionales con el fin de determinar si la interpretación realizada es conforme o no con las exigencias de justicia de la Constitución, es decir, si su corrección no es solo formal, sino también material. Por eso, en este caso, centraremos el análisis en la calificación de la prostitución como un trabajo conforme con la dignidad humana, y susceptible de especial protección constitucional y legal.

\section{El derecho fundamental al trabajo y su regulación jurídica}

La Constitución política del Perú y la de Colombia coinciden en calificar al trabajo como un derecho y un deber de sus ciudadanos ${ }^{19}$. Respecto a la libertad de elegir trabajo u oficio, la Constitución colombiana establece que "toda persona es libre de escoger profesión u oficio. La ley podrá exigir títulos de idoneidad. Las autoridades competentes inspeccionarán y vigilarán el ejercicio de las profesiones. Las ocupaciones, artes y oficios que no exijan formación académica son de libre ejercicio, salvo aquellas que impliquen un riesgo social" ${ }^{20}$. Mientras que la peruana se limita a señalar que "toda persona tiene derecho a trabajar libremente, con sujeción a ley"21.

Ni la Constitución del Perú ni la de Colombia mencionan la prostitución, pero ambas se pronuncian en idénticos términos contra "la esclavitud, la servidumbre y la trata de seres humanos en cualquiera de sus formas" 22 . La Constitución peruana, además, advierte que "ninguna relación laboral puede limitar el ejercicio de los derechos constitucionales, ni desconocer o rebajar la dignidad del trabajador" ${ }^{23}$. Mientras tanto, la colombiana señala que no son de libre ejercicio los oficios que impliquen "un riesgo social”, y que "toda persona tiene derecho a un trabajo en condiciones dignas y justas" 24 . 
El rol del trabajo es fundamental en el desarrollo humano: así lo expresa el último informe publicado del Programa de las Naciones Unidas para el Desarrollo sobre esta cuestión. Para esta organización "la calidad del trabajo es una dimensión importante para lograr que el trabajo mejore el desarrollo humano. Sin embargo, problemas como la discriminación y la violencia impiden que se establezcan vínculos positivos entre el trabajo y el desarrollo humano" ${ }^{25}$. La responsabilidad del Estado y de la sociedad debe fomentar el desarrollo humano por medio del trabajo, lo cual requiere políticas y estrategias en tres esferas generales: crear oportunidades de trabajo, garantizar el bienestar de los trabajadores, y adoptar medidas específicas. Con ello se pretende enfrentar los desequilibrios del trabajo remunerado, y gestionar políticas especiales para grupos más vulnerables - los jóvenes, las personas con discapacidad y las mujeres-, cuya situación es de clara desventaja en el mundo laboral ${ }^{26}$.

Se entiende, entonces, que la Constitución peruana califique al trabajo como la "base del bienestar social y un medio de realización de la persona" ${ }^{27}$. El concepto jurídico-laboral del término trabajo implica observar los requisitos generales de todo negocio jurídico: agente capaz, fin lícito, objeto física y jurídicamente posible, y observación de la forma prescrita ${ }^{28}$.

Esta protección ha llevado a establecer las normas mínimas de derecho necesario - la edad mínima para trabajar, las jornadas máximas a salario regular, los descansos semanales y anuales remunerados-, así como a prohibir el trabajo forzoso. Esta tutela jurídica responde a su carácter personalísimo ${ }^{29}$, así como a su función dinamizadora de la personalidad humana y de la vida social. El trabajo no se agota en parámetros económicos, al contrario, el mérito del derecho del trabajo es proteger su dimensión humana, pues este permite desarrollar el proyecto personal de vida. Más aún, la persona descubre su propia dignidad y la de los demás al trabajar, pues encuentra el modo de ser útil socialmente.

El trabajo "permite a los ciudadanos participar plenamente en la sociedad y les confiere un sentido de dignidad y valía personal. El trabajo puede contribuir al interés público; y el trabajo que implica cuidar a otras personas fomenta la cohesión y crea vínculos en las familias y las comunidades. El trabajo también consolida las sociedades. Los seres humanos que trabajan juntos no solo aumentan su bienestar material, sino que también atesoran un amplio conjunto de conocimientos que constituyen el fundamento de las culturas y las civilizaciones" ${ }^{\text {30 }}$. Sin embargo, "algunos tipos de trabajo llevados a cabo en determinadas condiciones perjudican el desarrollo humano. Muchas personas realizan trabajos que limitan sus opciones de vida. Millones de personas trabajan en condiciones abusivas y de explotación que violan sus derechos humanos fundamentales y destruyen su dignidad" ${ }^{\prime 3}$.

De allí, la necesidad de la institución de la irrenunciabilidad a los derechos reconocidos en las leyes laborales ${ }^{32}$. A diferencia de lo que ocurre en el derecho civil, donde prima el principio de autonomía de la voluntad, en el ámbito laboral, constituye la excepción. De este modo, el ordenamiento laboral "establece la imposibilidad de renunciar a los derechos que las leyes sociales reconocen a los trabajadores, ya que estas constituyen el mínimo necesario para que el trabajo se preste en condiciones apropiadas a la dignidad humana. De este modo se impide que el empresario someta a los trabajadores a renunciar a los derechos que las normas laborales les reconocen. Su evolución ha sido similar en los países occidentales y su vigencia se mantiene incólume" ${ }^{33}$. La doctrina jurídica la ha definido como "el instrumento de garantía efectiva del disfrute de los derechos de contenido laboral por parte de quien ostenta en la relación de trabajo una posición de subordinación jurídica" ${ }^{34}$. La incapacidad de renunciar a los derechos fundamentales ha sido el mecanismo que ha permitido el progreso en su defensa: el caso más evidente es el de la esclavitud. Es irrelevante el consentimiento a ser esclavo que alguien pueda prestar: los ordenamientos jurídicos democráticos, no admiten esa posibilidad. Se trata de mínimos indisponibles que resguardan el respeto debido a la dignidad humana.

Por lo expuesto hasta el momento, resulta evidente que el trabajo es un medio esencial para la realización de la persona y su ejercicio se encuentra directamente vinculado al respeto a la dignidad humana, al libre 
desarrollo de la personalidad, y a la solidaridad social. El Derecho Laboral, para defender estos derechos fundamentales, proyecta su tutela sobre la libertad del trabajador desde el momento en que celebra el contrato $^{35}$.

Esa tutela le permite al trabajador extinguir el contrato antes de su vencimiento y también preserva "una cierta libertad espacial de movimientos del trabajador", así como una limitación en la dependencia, a "lo debido en razón del oficio" ${ }^{36}$. Estas condiciones son necesarias para asegurar que en la ejecución del contrato no haya "mengua de la dignidad de quien trabaja" ${ }^{37}$, puesto que los atentados a la dignidad no solo se originan en "las violaciones groseras del principio de igualdad" - manifestadas en discriminaciones basadas en circunstancias personales irrelevantes para la prestación de servicios-, sino también por "los intentos de penetración en la intimidad del trabajador" ${ }^{38}$. Por eso existe una protección especial para evitar el acoso sexual en las empresas, con fuertes multas a los empresarios que no prevengan y neutralicen este tipo de conducta ${ }^{39}$.

La senda jurídica que ha conducido a respetar la libertad y la dignidad del trabajador no sólo ha permitido prohibir los sistemas de esclavitud o servidumbre, sino que condujo a tres consecuencias adicionales en base a las cuales se ha estructurado el ordenamiento laboral ${ }^{40}$. Estas premisas, tal como he expuesto en otra oportunidad, son ${ }^{41}$ : La primera, consiste en distinguir entre los servicios prestados y la persona que los presta. La segunda, en que, por el contrato de trabajo, el trabajador cede un tiempo de su vida para trabajar, pero no todo su tiempo, ya que, de hacerlo, el contrato sería invalido por la renuncia a los ámbitos personalísimos, en los que se despliegan los derechos fundamentales. Y, finalmente, la tercera, que la cesión que realiza el trabajador no es de toda su actividad, sino únicamente de la que se ha comprometido por medio del contrato. Por esta razón, Alonso Olea pudo afirmar que lo característico del contrato de trabajo, desde su perspectiva histórica, "no es la relación de subordinación o dependencia del trabajo, sino su limitación paulatina" ${ }^{42}$.

De lo anteriormente expuesto se deduce que el derecho al trabajo no solo tutela la subjetividad de quien trabaja para otro, sino también su dignidad y, consecuentemente, sus derechos fundamentales ${ }^{43}$. Y, por eso, sus disposiciones no protegen, las prestaciones de servicios, dependientes y por cuenta ajena, cuyo objeto sea reducir al trabajador a un objeto de uso o aprovechamiento, sin dejarle margen de intimidad personal, siendo irrelevante el consentimiento que hubiese podido $\operatorname{prestar}^{44}$.

\section{La prostitución, el libre desarrollo de la personalidad y el principio de no discriminación}

El ordenamiento peruano y el colombiano coinciden en no mencionar la prostitución en el texto constitucional, pero sí tipifican como delito inducir a una persona al lenocinio, sea menor o mayor de edad ${ }^{45}$. Se entiende por prostitución la "actividad de quien mantiene relaciones sexuales con otras personas a cambio de dinero" ${ }^{26}$. Frente a ella, los ordenamientos jurídicos han optado por prohibirla o reglamentarla; y en los últimos decenios, desde algunos sectores, se impulsa su aprobación y promoción al equipararla con otros oficios $^{47}$.

Se admite pacíficamente por la doctrina científica - aunque se trivialice en algunos medios de comunicación y en cierta literatura-, que la sexualidad humana se diferencia de la animal, pues la primera "no se reduce a la satisfacción de un instinto, sino que es la más alta expresión de donación corporal y afectiva, que compromete a la persona en su dimensión más íntima ${ }^{48}$. En cambio, cuando la sexualidad se ejerce en el ámbito de la prostitución, se excluye el componente propiamente humano, puesto que el cliente paga un precio con el fin de utilizar a la persona que se dedica a la prostitución para satisfacer sus instintos, convirtiéndola así en objeto de una relación, no en sujeto" ${ }^{49}$. Se entiende, pues, que la Organización Panamericana de la Salud 
haya concluido que "la prostitución representa una forma de esclavitud incompatible con la dignidad de la persona y con sus derechos fundamentales"

Desde el Comité de América Latina y el Caribe para la Defensa de los Derechos de las Mujeres (Cladem), se ha enfatizado que, por ser la prostitución femenina una práctica milenaria, no se debe concluir que sea socialmente tolerable, porque equivaldría a "aceptar que el cuerpo femenino es una mercancía, un ente sin mente, sin sujeto; por tanto, sin derechos; es la división absoluta del cuerpo y el ser, donde este último no cuenta. El ejercicio del poder está claramente definido a favor del varón, quien, además de disfrutar del cuerpo de la mujer, se permite ejercer todo tipo de violencia en su contra (...)" 51 . Calificar como digna una actividad únicamente por la autodeterminación de quien la realiza, implica convertir la dignidad humana en un concepto vacío, que cambia de contenido según el arbitrio del sujeto. Se puede afirmar, que del mismo modo que consentir en la esclavitud no la convierte en compatible con la dignidad humana, tampoco lo hace la razonada determinación de ejercer un oficio que conlleve "una forma de explotación caracterizada por la violación total de todos los derechos y por el sometimiento permanente de las mujeres a tratos crueles, inhumanos y degradantes" 52 . Por eso, si bien la prostitución puede ser calificada como oficio en cuanto constituye una ocupación habitual ${ }^{33}$, no puede ser considerada como trabajo porque no cumple con los estándares de respeto y de desarrollo de la persona humana que las constituciones occidentales, verdaderamente democráticas, reconocen a este término, que tiene un preciso contenido jurídico y es el eje del desarrollo personal y social ${ }^{54}$.

Por otro lado, se debe destacar que muchas mujeres se dedican a este oficio por la falta de programas estatales que las capaciten para acceder a un mercado laboral globalizado y competitivo, en el que puedan generar ingresos suficientes; por eso, "paradójicamente, continúan ejerciendo la prostitución por cuanto obtienen ingresos superiores " 5 ". Además del factor económico, existen otros elementos determinantes, como son la falta de capacitación, la violencia social e intrafamiliar, la delincuencia, la violencia y el abuso sexual, el alcoholismo y la drogadicción ${ }^{56}$.

El Tribunal Constitucional peruano hizo una distinción entre la prostitución clandestina y la que no lo es. La primera es la que no se ajusta a esas disposiciones administrativas, y la segunda es la que se ejerce de acuerdo con las Ordenanzas Municipales ${ }^{57}$. En Colombia, en cambio, la Corte Constitucional ha realizado una amplio análisis para interpretar que, al no estar tipificada como delito, el lenocinio se convierte en objeto lícito de contratación; y concluye que, debido a que las prostitutas constituyen un colectivo históricamente vulnerable, se debe proteger especialmente el ejercicio de la prostitución, tanto si es realizado en forma independiente como cuando se realiza en situación de dependencia y subordinación, que sirva como medio de pago de una retribución ${ }^{58}$.

La Corte colombiana no ha podido negar la connotación distinta que tiene el ejercicio de la prostitución frente a los demás oficios y actividades que son merecedores de tutela laboral, pero también reconoce que no debe ser fomentada, lo cual implica una contradicción 59 . Por eso, la Corte afirma que "si bien es cierto que la práctica de la prostitución ya no es un delito, sí lo es la de quienes la promueven, siendo mayor la pena cuando las víctimas son menores de edad" Además, esta labor ha sido objeto de diversos pronunciamientos de los Estados ante su creciente desarrollo, esto por el profundo daño psicológico, moral y físico que produce ${ }^{60}$. En cambio, no constituye un delito enseñar a un menor de edad a coser, cocinar, segar, pintar, o cualquier otro oficio que pueda ser objeto de un contrato de trabajo porque es evidente que estos oficios - a diferencia de aquel-, potencian las capacidades auténticamente humanas. A su vez, lucrar abusivamente con el trabajo de menores será siempre reprobable, pero con una diferencia esencial: mientras la prostitución atenta contra la dignidad, pues reduce a la persona a un objeto de uso y abuso, las demás actividades en sí mismas consideradas, no lo hacen.

A criterio de la Corte colombiana, la incoherencia normativa se soluciona: 1) al equiparar el ejercicio de la prostitución con el trabajo, por el solo hecho de decidir hacerlo de forma libre y razonada ${ }^{61}$; 2) al calificarla 
como lícita, aun cuando no resulte concordante frente "a los ideales de una sociedad democrática y respetuosa de los derechos fundamentales, que anhela dignificar en el mayor nivel posible la vida y el desarrollo personal de los individuos en sociedad"62; 3) al señalar que no es obstáculo que determinada moral considere que el lenocinio es contrario a las buenas costumbres, ya que esta noción "no actúa como fuente paralela al Derecho positivo, sino conforme a él” ${ }^{63}$; y 4) al admitir que la prostitución es una actividad que está sometida a los parámetros constitucionales del principio general de libertad, de la propia dignidad humana como derecho fundamental, y en los principios del trabajo y de las libertades económicas que permiten "proveer de los recursos con qué satisfacer las necesidades personales y familiares, y aumentar el patrimonio" ${ }^{4}$. Concluye, finalmente, que al estar "controlada urbanísticamente y en términos de salubridad, ordenada en el comercio y sujeta a obligaciones tributarias, claras y específicas, permite a un número importante de personas ganarse la vida", lo cual legitima su objeto y contratación ${ }^{65}$.

Por otro lado, el eje de argumentación de la Corte se centra en los conceptos de dignidad humana y del libre desarrollo de la personalidad. Por este último se entiende: "vivir como se quiera y vivir bien (ganarse la vida)" de modo que cada uno decida. Por ello "no es admisible disponer ex novo, a partir de una moralidad de jueces, la ilicitud de aquellos acuerdos, cuando en la prestación u obligación que se analice se han cumplido a cabalidad con los principios y como decisión propia, autónoma, sin afectación de la integridad física o moral" ${ }^{66}$.

Si comparamos los argumentos esgrimidos en sede constitucional con los estudios de campo realizados hasta el momento por organismos internacionales públicos, o por entidades privadas, encontramos que, en oposición a lo que afirman los magistrados, se ha comprobado la falta de libertad en el ejercicio de este oficio, y daño moral y físico de quienes se dedican a él. La mayoría de la gente que se prostituye, lo hace por pobreza y por falta de oportunidades laborales. Son muy pocas las personas que afirman encontrar en este oficio un medio de desarrollo personal y familiar, y esa minoría no puede establecer una regla para las demás, en base a su experiencia personal ${ }^{67}$. El derecho no regula basado en excepciones: las normas se caracterizan por el carácter general de sus disposiciones que están ordenadas, a su vez al bien común.

La prostitución viola el principio de igual dignidad, ya que reduce a una persona a bien útil o mercancía en beneficio de otra. Entre los muchos estudios que se pueden citar en este sentido, hemos elegido el informe elaborado por la Comisión de Derechos de la Mujer e Igualdad de Género del Parlamento Europeo, que compendia la situación en la Unión Europea ${ }^{68}$. Ese informe confirma que "la presión bajo la cual se ejerce la prostitución puede ser directa y física, o indirecta, por ejemplo, a través de presiones sobre la familia en el país de origen, y puede consistir en una coacción psicológica insidiosa" ${ }^{69}$. Añade que, tanto la prostitución a secas — realizada en forma independiente-, como la prostitución forzada, están intrínsecamente ligadas a la desigualdad de género en la sociedad, porque la totalidad de usuarios de la prostitución es, en su mayoría, varones; mientras que la inmensa mayoría de las personas que se prostituyen son mujeres y niñas, que suman más de cuarenta millones de víctimas en todo el mundo.

El informe confirma que "la prostitución funciona como un negocio y crea un mercado en el que distintos actores están interconectados, y los proxenetas realizan cálculos y actúan para afianzar o aumentar sus mercados y maximizar los beneficios; y que los compradores de sexo desempeñan un papel fundamental, puesto que mantienen la demanda de este mercado" ${ }^{70}$. Pero, a diferencia de la Corte colombiana, la conclusión a la que llega la Comisión europea es que "los mercados de prostitución alimentan la trata de mujeres y niños, y conducen a un aumento de la violencia contra ellas, especialmente en aquellos países en los que la industria del sexo se ha legalizado"71.

También se ha comprobado que la prostitución y la trata de mujeres están relacionadas, pues a los clientes les es indiferente que las personas sean víctimas o no de la trata. Por eso, "si bien existe una diferencia entre prostitución forzada y prostitución voluntaria, es obvio que la prostitución es una forma de violencia contra 
la mujer" ${ }^{72}$. Pero esta diferencia es engañosa porque, como se demuestra en otros estudios, no existe tal voluntariedad en la mayoría de las personas que se dedican a este oficio ${ }^{73}$.

Con base en lo anterior, podemos concluir que no cabe equiparar la prostitución con el trabajo, que es deber y derecho de los ciudadanos, y medio de desarrollo personal y social. En consecuencia, no se vulnera el principio de igualdad y el de no discriminación cuando se da un tratamiento distinto a estas dos realidades, ya que el derecho no equivale al igualitarismo, sino a darle a cada uno lo que le corresponde de acuerdo con la naturaleza de las cosas y/o de las personas. Más aún, se violentaría la justicia con esa equiparación, porque no sólo se vacía de contenido la dignidad, sino que se vulnera la Constitución, que prohíbe el ejercicio independiente o dependiente de oficios que impliquen un riesgo social, y la prostitución se encuentra comprometida entre ellos ${ }^{74}$.

Afirmar que el ejercicio de la prostitución es compatible con el respeto a la dignidad humana, y que es "una expresión del libre desarrollo de la personalidad", contradice la opinión de los expertos que señalan que el lenocinio, esté unido o no a la trata de personas, tiene "consecuencias físicas y sicológicas devastadoras y duraderas, incluso después de haber cesado la prostitución, para los individuos que se ven implicados en ella, especialmente niños y adolescentes, además de ser, a la vez, causa y consecuencia de la desigualdad de género, y de perpetuar los estereotipos de género y el pensamiento estereotipado sobre las mujeres que venden sexo, como la idea de que el cuerpo de las mujeres, y menores de edad, está en venta para satisfacer la demanda masculina de sexo"75. En este oficio, el cuerpo de la mujer se reduce a mercadería, es decir a objeto, desconociendo que el cuerpo no es una cosa: es la misma persona. Y, el cliente que es quien paga por usar el cuerpo de la mujer, "tiene la propiedad de satisfacer necesidades, propiciar gratificación sexual, (...), y ella, en la venta del cuerpo, busca la supervivencia” ${ }^{76}$. Esto es lo que ocurre en la realidad: ya que la conducta — tanto del cliente como de la persona que se prostituye-, no sólo no es observable al momento de "cumplirse con la prestación", a diferencia de lo que ocurre con los demás oficios de carácter laboral, sino que por cumplir con la prestación exige no dejar margen alguno para la intimidad personal.

Por otro lado, no puede equipararse la remuneración con el pago que realiza el cliente o el proxeneta, porque en el ámbito laboral existe una clara diferencia entre la actividad y la persona que presta el servicio, que debe ser tratada con dignidad, respetando su intimidad, es decir, como a un ciudadano de primer nivel. Entre el trabajador y el empleador no hay relación de dominio, sino una subordinación que se limita a la debida por razón del oficio, al ser una relación jurídica entre pares. Por eso, la remuneración no convierte al trabajo en una mercancía ${ }^{77}$, ni al trabajador en un mercenario o esclavo, a diferencia de lo que ocurre en la prostitución.

El ejercicio del oficio de la prostitución constituye el punto de partida más lejano de la meta del trabajo decente, propuesta por la OIT en 1999, el cual "sintetiza las aspiraciones de las personas durante su vida laboral. Significa la oportunidad de acceder a un empleo productivo que genere un ingreso justo, la seguridad en el lugar de trabajo y la protección social para las familias, mejores perspectivas de desarrollo personal e integración social, libertad para que los individuos expresen sus opiniones, se organicen y participen en las decisiones que afectan sus vidas, y la igualdad de oportunidades y trato para todos, mujeres y hombres"78. El trabajo protegido constitucionalmente, es el que se asienta en el respeto a la dignidad ajena, entendida no cómo simple autodeterminación, independiente del objeto de la acción del sujeto, sino como una norma ética que tiene ínsito el deber de "tratarse a sí mismo y tratar a todos los demás nunca como simple medio sino siempre al mismo tiempo como fin en sí mismo"79. En otras palabras, no podemos retroceder a épocas arcaicas, en las que se admitía que unos seres humanos fueran objeto de uso y disfrute de otros, desconociendo así la igual dignidad ${ }^{80}$.

La voluntariedad en el ejercicio de la prostitución, también en una persona mayor de edad, no anula sus efectos nocivos. La Unión Europea hace "hincapié en que la prostitución forzada, la prostitución y la explotación en la industria del sexo tienen consecuencias físicas y sicológicas devastadoras y duraderas, incluso después de haber cesado la prostitución, para los individuos que se ven implicados en ella (...)" ${ }^{\text {81 }}$. La razón 
estriba en que el modo en que se ejerce una profesión desarrolla unos hábitos de actuar, que configuran el perfil ético de una persona y, por lo tanto, el de una sociedad, puesto que la acción humana se desarrolla en sociedad y repercute en ella ${ }^{82}$.

Finalmente, es necesario distinguir entre el ejercicio de un derecho y la simple acción libre. Afirmar que una conducta, no reconocida en el ordenamiento positivo, constituye el ejercicio de un derecho, implica que hay un título de tipo natural, es decir, anterior al Estado, que debe ser respetado y reconocido por la legislación. Sin embargo, no hay título que faculte a una persona a usar y disfrutar de otra, como si fuera una cosa, pues equivaldría, como ya hemos afirmado, a desconocer la igual dignidad. En definitiva, así como no se puede afirmar que existe el derecho a prostituirse, porque no existe el deber de acceder a la petición de trato sexual, tampoco existe el derecho al suicidio, ya que no existe el deber de matar a quien desee quitarse la vida: ambas acciones son parte del agere de los individuos ${ }^{83}$.

La situación de violencia en la que se encuentran las personas prostituidas, unida al aumento del crimen organizado y otros problemas sociales, ha llevado a algunos Estados a plantear acciones de reinserción social para quienes libremente decidan abandonar la prostitución ${ }^{84}$. Por eso resulta contradictorio que el Estado invierta fondos públicos en "reincorporar" a la vida social a quienes han ejercido la prostitución y, a la vez, conceda protección jurídica a quienes se dediquen a esta profesión, como si su práctica no afectase su inserción social.

En España, en el año 2004, se concedió licencia de funcionamiento a una cadena de hoteles, denominada "Mesalina”, para el ejercicio independiente de la prostitución. Pocos meses después, Wassyla Tamzali, exdirectora del Programa de la Mujer de la Unesco, declaró en el Ayuntamiento de Madrid que España es el país de la Unión Europea en el que es más fácil ejercer la prostitución porque "la prostitución está industrializada, y eso no ocurre en ningún otro país del mundo, hay que poner obstáculos a la prostitución en lugar de hacer autopistas que atraen a más clientes y más prostitutas" ${ }^{85}$. Cuatro años más tarde, un estudio puso de manifiesto que "regular la prostitución como una profesión tendría graves problemas jurídicos, tanto en materia de derechos fundamentales, como laborales y de contratación civil" ${ }^{86}$. Y, de hecho, en la actualidad, "España es el país europeo con mayor demanda de sexo pagado y el tercero a nivel mundial" ${ }^{87}$.

Está demostrado que la trata de personas se encuentra directamente relacionada con el ejercicio de la prostitución $^{88}$. Por otro lado, se debe insistir ${ }^{89}$ en que en los últimos decenios se advierte "laxitud de los discursos académicos, de las disposiciones legales y la ambigua y engañosa jerga de las instituciones" ${ }^{\prime 2}$. En este sentido, los organismos internacionales han disfrazado la realidad con términos considerados neutros, utilizando un lenguaje encubridor. Este se aprecia inclusive en el de la Organización Mundial de la Salud (OMS), que "comenzó a tratar el tema de la prostitución con el aséptico rótulo de "trabajo sexual", sin ninguna fundamentación. En su publicación The Sex Sector, la Organización Mundial del Trabajo (OIT), sostiene que la existencia de la llamada industria sexual es un hecho justificado por el dinero que produce" ${ }^{\text {. }}$.

Si este fuera el criterio determinante para establecer la legitimidad de una actividad, entonces - ante el movimiento económico que logran el tráfico de armas y el de las drogas-, estaría justificada la legalidad de esas actividades y el pago de impuestos, para repartir la riqueza generada. Sin embargo, no se requiere especial clarividencia para advertir que esa política de Estado no estaría al servicio de la persona, sino de la producción de riqueza; esto haría que se olvide que la persona vale por sí misma, y no por su capacidad de producir riqueza o de consumirla. El Estado no puede ignorar el daño objetivo que produce a la persona y a la sociedad este tipo de actividades, ya sea por la violencia, la degradación de costumbres, o de la salud física y mental de quienes se encuentren dentro de estas redes. El deber fundamental de un Estado y una sociedad es respetar la dignidad humana, de acuerdo con los valores objetivos constitucionales, sin desdibujar el rostro de lo auténticamente humano con argumentos utilitarios.

Las autoridades de Holanda, país que tiene en la industria sexual una de sus más importantes fuentes de recursos, propuso un nuevo concepto para lograr la legitimación de esta profesión: "el pleno consentimiento 
a la propia explotación", y sentaron como premisa que "la legitimidad de tal comercio ya no se discute" ${ }^{92}$, lo cual es falso. Sin embargo, esta ha sido la línea argumental elegida por la Corte constitucional de Colombia en las sentencias sobre este tema.

Se ha afirmado con frases contundentes, que calificar el acuerdo de prostitución como un contrato equivale a "legitimar una lógica infame de dominio. La relación entre mujeres y varones es una relación asimétrica de dominio y opresión, que llega al máximo en la compra sexual de personas en prostitución" ${ }^{33}$. En todo caso, el ejercicio de la prostitución no es admisible, con independencia del sexo de los agentes, puesto que una persona sea usada por otra "para consumo sexual —al igual que fuera una gaseosa - es como el máximum de la cultura individualista del neoliberalismo que denigra a la humanidad" ${ }^{94}$. Por otro lado, como en la prostitución la mayoría son mujeres, con la excusa de no discriminar a las mujeres en situación de prostitución, se "esconde y legitima el tráfico, la trata y el proxenetismo" 95 . En todo caso, detrás de las presiones por cambiar el lenguaje y referirse a "la industria del sexo", el "sexto sector" o "las trabajadoras sexuales", existen grandes intereses económicos que se presentan como defensores de derechos de las mujeres, cuando en la realidad sucede lo contrario ${ }^{96}$.

\section{El concepto de dignidad humana como fundamento del orden social}

La Constitución del Perú reconoce que "la defensa de la persona humana y el respeto de su dignidad son el fin supremo de la sociedad y del Estado ${ }^{97 ”}$. Mientras que en la de Colombia el Estado social de derecho del país se funda en "el respeto de la dignidad humana, en el trabajo y la solidaridad de las personas que la integran y en la prevalencia del interés general"98.

Existe un consenso unánime en la jurisprudencia constitucional — del derecho comparado y en la doctrina jurídica-, sobre el rol fundamental que le corresponde a la dignidad humana, como principio-deber del orden social; pero, a la vez, hay una disparidad de criterios, inclusive contradictoria, cuando se interpreta el contenido y alcance de los derechos inherentes a esa dignidad.

Desde hace muchos años he comprobado que algunos aluden al respeto a la dignidad humana para justificar la eutanasia e imponer, inclusive, el deber de matar a quien manifieste su voluntad de suicidarse y no pudiera hacerlo por sí mismo. Mientras otros invocan ese mismo respeto para impedirla y, más bien, ayudar a quien no le encuentra sentido a su vida o no sabe cómo resolver las dificultades que enfrenta, a superar ese estado mitigando sus sufrimientos. También se alega ese respeto para legalizar el aborto eugenésico, al considerar que las personas discapacitadas no tendrían una calidad de vida acorde con la dignidad humana, mientras otros invocan esa dignidad para defender esas vidas y brindarles luego mayor protección y ayuda social.

Ante posturas tan radicalmente opuestas, es necesario precisar en qué consiste la dignidad humana, para ello, recogeré a continuación algunos datos y conclusiones a los que llegué al analizar el rol que el respeto a la dignidad humana ha desempeñado en el desarrollo del derecho del trabajo ${ }^{99}$, para luego compararlos con los criterios de la Corte Constitucional de Colombia al respecto. En primer lugar, la dignidad de la persona es, ante todo, un juicio que se emite sobre el valor de su estructura específica ${ }^{100}$. Por otro lado, desde el punto de vista filosófico-jurídico, es un concepto que se inscribe en tres planos: en el de la naturaleza de la persona, en su fundamento, y en las exigencias jurídico-naturales que se siguen a esa naturaleza ${ }^{101}$. Puede decirse que la dignidad se fundamenta en el modo de ser propio de la persona, que tiene inteligencia, voluntad y un carácter relacional, ya que no puede alcanzar su desarrollo en solitario. Por tanto, está fundamentada en esa naturaleza y en las exigencias de conducta que de ella se siguen. Por otro lado, la dignidad tiene un carácter axiomático, ${ }^{102}$ que no facilita su expresión conceptual. Sin embargo, se percibe intuitivamente por ser una cualidad simple ${ }^{103}$, es decir, evidente por sí misma. Asimismo, para obrar conforme a esa dignidad es necesario un juicio de razón 
sobre cómo satisfacer las necesidades propias y ajenas ${ }^{104}$. Por eso se ha dicho que "aunque nacemos hombres, tenemos que aprender a ser humanos"105.

Si bien es cierto, la racionalidad y la libertad son características exclusivas del obrar humano, y son una manifestación de su dignidad, no son el índice que permite diferenciar entre individuos con o sin dignidad ${ }^{106}$. Aceptar esta premisa equivaldría a desconocer que la dignidad humana es un atributo heterónomo, es decir, que no depende de la voluntad del individuo ni de la sociedad. Más bien, es un atributo inherente a la condición de miembro de la familia humana, sin discriminación alguna, tal como reconoció la Declaración Universal de los Derechos Humanos ${ }^{107}$. Y esa dignidad explica que existan instituciones como la tutela y la curatela, que protegen los derechos de las personas que no están en condiciones de hacerlo por sí mismas. La historia demuestra que equiparar la dignidad con la autonomía de la voluntad reduce el deber de respeto en beneficio de los más fuertes: basta recordar la experiencia nazi.

El concepto de dignidad de la persona se originó en una visión trascendente de la vida, como hemos visto antes, que se mueve en el dualismo del ser y del deber, en el que es la razón, la que le permite identificar cuál es la conducta acorde con la dimensión humana. Esto ha sido así desde los orígenes de la humanidad. Un claro testimonio se encuentra en la poesía didáctica de Hesiodo (s. VIII a.C.) quien enseña a sus oyentes: “...presta atención a la justicia y olvida por completo la violencia. Pues el Crónida puso esta norma para los hombres: para peces, fieras y pájaros voladores, comerse unos a otros, puesto que no hay justicia en ellos, pero a los hombres les dio justicia que es más provechosa; pues si alguien, una vez que las conoce, quiere proclamar las cosas justas, a ése Zeus, de amplia mirada, le da felicidad, pero quien en sus testimonios se engañe perjurando voluntariamente y al mismo tiempo dañando a Dike, se extravía de manera incurable..." ${ }^{108}$. La relación entre la razón, la justicia y la divinidad ha sido percibida desde antiguo y, de hecho, el concepto de dignidad humana es de tipo metafísico-religioso ${ }^{109}$, que surgió en la teología católica al desarrollar la idea de persona en Dios y luego en el ser humano, en cuanto creado a imagen y semejanza de la divinidad ${ }^{110}$. El reconocimiento de una particular densidad de la presencia divina en cada individuo desarrolló el deber de respeto erga omnes, con un cierto carácter excepcional ${ }^{111}$.

En cambio, el concepto de la dignidad como fundamento de los derechos humanos es posterior. Kant, conocido como el teórico de la dignidad, definió ésta en relación con la capacidad de auto legislación personal, y con el cumplimiento del deber ${ }^{112}$ y la superación del estado de naturaleza, pero sin relación con la trascendencia. De este modo, el fundamento de la dignidad dejó de ser heterónomo para convertirse en autónomo y, por ende, sujeto a las reglas del consenso social y perdió, su carácter universal e inviolable, tal como se puede apreciar en algunas legislaciones que admiten la eliminación de sujetos inocentes por motivos subjetivos o por conveniencias económicas, o consolidan sistemas de trabajo poco acordes con el verdadero desarrollo humano, por motivos económicos.

Se puede afirmar que en la actualidad, el pensamiento de Kant sobre la dignidad humana ha logrado: i) relacionar la capacidad de autodeterminación con la dignidad; ii) maximizar el respeto de toda persona erga omnes precisamente por tener dignidad; iii) distinguir entre lo que es intercambiable y lo que tiene dignidad; y finalmente, iv) la diferencia esencial cualitativa y no cuantitativa con los demás seres naturales y artificiales, porque mientras estos pueden ser medio para conseguir algo, el ser humano no, porque es un fin en sí mismo ${ }^{113}$.

Sin embargo, al privilegiar la utilidad y autonomía del sujeto — volenti non fit injuria -, se ha olvidado el imperativo moral kantiano, según el cual la conciencia sólo puede admitir una ley impuesta por ella misma, cuando sea de tal calidad ética que pueda erigirse en ley universal ${ }^{114}$.

La jurisprudencia de la Corte Constitucional que estamos analizando sigue este pragmatismo, porque privilegia la autodeterminación, pero desgajada del imperativo categórico kantiano antes mencionado y desvinculada de la naturaleza y de los bienes humanos básicos ${ }^{115}$, ya que define el libre desarrollo de la personalidad como "vivir como se quiera y del vivir bien (el ganarse la vida)", es decir, obtener el sustento 
diario sin más limitaciones que la propia determinación ${ }^{116}$. Es por esta razón que admite "la licitud de la prostitución en sus diversas manifestaciones, si se está partiendo del supuesto de que en su ejercicio media de modo íntegro y persistente la voluntad libre y razonada, en particular de la persona que vende el trato sexual" ${ }^{117}$. La consecuencia de este razonamiento es que la arbitrariedad sustituye a la justicia, ya que no se otorga a cada quien lo que le corresponde por derecho, sino lo que su arbitrio decida.

La autonomía de la voluntad, concebida en estos términos, busca la emancipación total -inclusive de la propia naturaleza-, y con ella, la reducción del derecho a yuxtaposiciones de cuotas de arbitrariedad toleradas $^{118}$. Sin embargo, la experiencia demuestra que la libertad no es ilimitada. Esta se encuentra condicionada por un modo de ser, que exige unos bienes básicos para ser feliz y realizarse plenamente ${ }^{119}$, y a su vez, solo se consiguen en una acción mancomunada, "estrictamente colectiva y progresiva, que se realiza gradualmente en el tiempo, a través de la convivencia social" ${ }^{120}$. Por eso, si bien la autodeterminación constituye una exigencia de la dignidad humana, no se reduce a ella ${ }^{121}$.

El individualismo moderno convierte la autonomía moral en una autarquía estoica, en donde la libertad es independiente de los otros, y en la que la persona es fundamentalmente consciente, y puede manipular su cuerpo y la naturaleza a su voluntad, exigiendo que los demás acepten y respeten sus decisiones, aunque vayan en contra de la solidaridad o el interés general ${ }^{122}$. Este individualismo lleva a identificar pretensiones con derechos, como en el caso de la prostitución, puesto que es falso que exista un título natural que permita exigir el reconocimiento del derecho a prostituirse. Más bien, se tergiversa la naturaleza de los derechos al presentarlos como reivindicaciones de la propia esfera de poder del individuo frente a los otros, sin conciencia de la interdependencia de los derechos y de los deberes ${ }^{123}$.

Se llega así a la paradoja de defender la prostitución en nombre de la dignidad y de la tolerancia, cuando la dignidad se caracteriza por ser aquello que no tiene precio ${ }^{124}$, mientras que la prostitución consiste, precisamente, en pagar un precio para utilizar a una persona, suprimiendo las barreras de su intimidad y reduciéndola a un objeto de uso para satisfacer el placer sexual del cliente. La prostitución es un oficio indigno para el ser humano, no porque así lo reconozca una religión determinada, sino por ser contraria a los bienes humanos básicos ${ }^{125}$. Si, además, alguna confesión religiosa confirma esta valoración, entonces habría que acogerla, del mismo modo que hay respetar, pero no secundar, aquellas otras que no reconocen la igual dignidad, sea por un sistema de castas o por considerar a la mujer inferior al varón ${ }^{126}$. A la vez, una sociedad pluralista y democrática no puede, ni debe, ser confesional o fundamentalista, pero tampoco puede dejar de tener convicciones ${ }^{127}$, porque ello lleva a la tiranía, la intolerancia o a la degradación social, al querer una sociedad de pensamiento único, en el que se descalifica a quien no comparte las propias convicciones.

No se puede olvidar que, para resolver las cuestiones jurídicas de mayor relieve, es necesario realizar una opción moral, aun cuando la Moral y el Derecho no se identifiquen ${ }^{128}$. La neutralidad axiológica no existe en las decisiones jurídicas, porque cualquier postura que se adopte tiene implícita una concepción de lo humano y un código moral, aunque los tribunales pretendan presentarse como asépticos en cuestiones relacionadas con la moral pública y las buenas costumbres ${ }^{129}$.

Si se quiere evitar los tratos degradantes e inhumanos, tal como lo establecen las Constituciones peruana y colombiana $^{130}$, los Estados no pueden limitarse a no promover la prostitución o a no facilitar su práctica. Entre las soluciones implementadas es ilustrativa la fórmula ideada en Suecia, luego adoptada por los otros países nórdicos y más recientemente adoptada por Francia. Esta política consiste en imponer multas a los clientes, que van de los 1500 a los 3750 euros, si son reincidentes y al fichaje e, inclusive, a imponer la pena de cárcel. Además, se les obliga a seguir un curso de sensibilización sobre la situación de las prostitutas ${ }^{131}$. No se castiga a quien ejerce la prostitución, sino más bien se le ofrece, si es extranjera y quiere abandonar la prostitución, un permiso de residencia. Se ha destinado un fondo para acciones de reinserción social y laboral de 4.8 millones de euros anuales. Se estima que en Francia hay, al menos, 30.000 mujeres dedicadas a la prostitución, que son 
extranjeras en su gran mayoría ${ }^{132}$. La experiencia de estos países es favorable: ha aumentado el número de clientes sancionados y disminuido la prostitución callejera, a la vez que no se ha detectado un aumento del tráfico sexual y de la explotación de personas, en particular menores de edad ${ }^{133}$.

En cambio, en Alemania, donde se ha legalizado su práctica, no sólo no se ha conseguido reinsertar a esas mujeres, sino que el negocio se ha expandido: hay muchas más prostitutas y son muy pocas las que se han afiliado a la Seguridad Social ${ }^{134}$. A la vez, desde el 2000 hasta el 2011 bajaron las condenas a proxenetas de 151 a solo 32 porque resulta muy difícil probar el delito ${ }^{135}$. Así lo ha reconocido expresamente el Parlamento Europeo en el informe elaborado sobre este tema, en el que exhorta a los países miembros a aplicar el modelo nórdico y pone en evidencia el fracaso del alemán ${ }^{136}$.

\section{Conclusiones}

Toda decisión jurídica implica una concepción de lo humano y una moral determinada. Los jueces deben basar sus decisiones en la moral objetiva que ofrece la Constitución, interpretando las normas directamente estatuidas en forma unitaria y sistemática. No es posible impartir justicia sin partir de un concepto de lo humano y de lo que es digno para la persona.

La dignidad humana no es un concepto vacío que se reduzca a una autodeterminación arbitraria. Su contenido responde a los bienes humanos básicos, que exigen un modo de actuar conforme a ellos.

El trabajo es un derecho y un deber, un medio de realización de la persona y la base del bienestar social. Por eso el Derecho Laboral, mediante el principio de irrenunciabilidad de derechos, protege al trabajador de sus actos propios, al evitar que admita ser reducido a un objeto de uso y explotación por quien detente mayor poder económico, para así preservar su intimidad personal.

La persona, por ser digna, no tiene precio, pero en la prostitución se paga para romper las barreras de la intimidad, y convertir a quien se prostituye en mercancía u objeto de uso para el cliente. En consecuencia, este oficio implica un sistema de esclavitud contrario a la dignidad humana y a la actividad denominada trabajo, protegida por el Derecho Laboral.

La prostitución y el proxenetismo son formas de violencia que incrementan la trata de personas y el crimen organizado. Las naciones que han legalizado la prostitución aumentan su PIB con un sistema de explotación en el que crece exponencialmente el número de personas prostituidas, pero disminuyen el de las condenadas por proxenetismo. En cambio, las que sancionan con multas a los clientes y han invertido fuertes sumas en programas de reinserción social, han reducido considerablemente la prostitución callejera y el número de prostitutas.

Las sentencias T-629 de 2010 y T-594 de 2016 de la Corte Constitucional de Colombia -que consideran la prostitución como un trabajo que merece especial protección jurídica, por ser expresión de la autodeterminación de la persona, y haber sido marginado socialmente-, son contrarias a las exigencias de la justicia contenidas en las disposiciones de las constituciones de Colombia y Perú, por lo que no obligan a los tribunales peruanos a secundar esa interpretación.

\section{Bibliografía}

Alfredo Montoya Melgar, Derecho del Trabajo (Tecnos, 2014).

Álvaro Rojas, Prostitución: la ley sola no arregla el problema. (ACEPRENSA, 2014).

Ana Marta González, La dignidad de la persona, presupuesto de la investigación cientifica, en Biotecnología, Dignidad y Derecho: bases para un diálogo, 17-41 (EUNSA, 2004).

Andrés Ollero, Democracia y convicciones en una sociedad plural (Navarra Gráfica Ediciones, 2001). 
Andrés Ollero, Derecho a la verdad: valores para una sociedad pluralista (EUNSA, 2005).

Andrés Ollero, Derechos humanos y metodología jurídica (Centro de Estudios Constitucionales, 1989).

Antonio Millán Puelles, Sobre el hombre y la sociedad (Rialp, 1976).

Augusto Medina Otazu, ¿Tienen derechos laborales las trabajadoras sexuales?, Soluciones Laborales, n. ${ }^{\circ}$ 99, 84-90 (2016). http://blog.pucp.edu.pe/blog/medinaotazu/wp-content/uploads/sites/259/2016/09/derechos-labora les-de-las-trabajadoras-sexuales.pdf

Bendicto XVI. Deus caritas est (Palabra, 2006).

Brenda Myers-Powell, Violada, baleada, apuñalada: "Sobreviví 25 años de prostitución", Mundo (2015) en http://www .bbc.com/mundo/noticias/2015/07/150623_25_anos_como_prostituta_finde_dv

Carlos Hakansson Nieto, Curso de Derecho Constitucional (Palestra, 2009).

Carlos Ignacio Massini, El derecho a la vida en la sistemática de los derechos humanos, en El derecho a la vida, 179-222 (C.I. Massini \& P. Serna eds., EUNSA, 1998). https://www.corteidh.or.cr/tablas/31473.pdf

Carmen Delgado Álvarez \& Andrea Gutiérrez García, Prostitución: notas para un análisis psicosocial de la coacción al consentimiento, en Igualdad. Retos para el siglo XXI, $37-56$ (2012). https://doi.org/10.13140/RG.2.1.3379.66 49

Cecilia Lipsyc, Mujeres en situación de prostitución: ¿esclavitud sexual o trabajo sexual?, en Prostitución: ¿̇trabajo o esclavitud?, 55-70 (CLADEM, 2003).

Cicerone, Etica e politica: Antologia dal De Officiis (Carlo di Spigno trad., 1972).

Código Penal de Colombia. https://perso.unifr.ch/derechopenal/assets/files/legislacion/1_20130808_01.pdf

Código Penal del Perú. https://diariooficial.elperuano.pe/pdf/0034/codigo-penal-29.07.2020.pdf

Código Procesal Constitucional. https://www.tc.gob.pe/tc/private/adjuntos/institucional/normatividad/codigo_pr ocesal.pdf

Constitución de la Organización Internacional del Trabajo (OIT). https://www.ilo.org/dyn/normlex/es/f?p=NOR MLEXPUB:62:0::NO::P62_LIST_ENTRIE_ID:2453907

Constitución Política de Colombia [Const]. Art. 6.7 de julio de 1991 (Colombia).

Constitución Política de Perú [Const]. 31 de octubre de 1993 (Perú).

Ernesto Benda, Dignidad humana y derechos de la personalidad, en Manual de Derecho Constitucional, 117-144 (Ernesto Benda et al. eds., Marcial Pons, 2001).

Esperanza y Otra vs. Ministerio de Defensa, Ministerio del Trabajo, Policía Metropolitana de Bogotá, Personería de Bogotá, Alcaldía Mayor de Bogotá y Procuraduría General de la Nación, No. T-594 -16. Acción de amparo de derechos fundamentales. (2016).

Gregorio Peces-Barba, La dignidad de la persona desde la Filosofía del Derecho, Cuadernos "Bartolomé de las Casas" (2.. ed. Dykinson, 2003).

Hesiodo, Teogonía; Trabajos y días; Escudo; Certamen (Adelaida Martín Sánchez y María Ángeles Martín Sánchez eds., Alianza Editorial, 2000).

Inmanuel Kant, Fundamentación de la metafísica de las costumbres (El Cid, 2003).

Inmanuel Kant, La metafísica de las costumbres (Adela Cortina Orts y Jesús Conill Sancho trads,. Madrid: Altaya, 1989).

Javier Hervada, Lecciones propedéuticas de Filosofía del Derecho (2.. ed., EUNSA, 1995).

Jesús Ballesteros, El individualismo como obstáculo a la universalidad de los derechos humanos, Revista Persona y Derecho, n. ${ }^{\circ} 41,15-28$ (1999). https://revistas.unav.edu//index.php/persona-y-derecho/article/view/32148

Jesús Ballesteros, Sobre el sentido del Derecho. Introducción a la Filosofía Jurídica (2.. ed., Tecnos, 1997).

John Finnis, Absolutos morales: tradición, revisión y verdad (Trad. Juan José García Norro). Barcelona: EIUNSA. (1992).

José María Sánchez Galera, El oficio menos libre del mundo, ACEPRENSA, (30 de octubre, 2015). https://www.acep rensa.com/sociedad/el-oficio-menos-libre-del-mundo/ 
José Morales, Teología de las religiones (Rialp, 2001).

Josef Pieper, ¿Qué significa "sagrado"? Un intento de clarificación (Rialp, 1990).

Joseph Ratzinger, Dios y el mundo. Creer y vivir en nuestra época. Una conversación con Peter Seewald (Galaxia Gutenberg, 2005).

Juan Carlos Romi, La prostitución: enfoque psiquiátrico, sexológico y médico-legal. Alcmeon, 13 Revista Argentina de Clínica Neuropsiquiátrica, n. ${ }^{\circ}$ 2, 5-28 (2006). https://www.alcmeon.com.ar/13/50/1_Romi.htm

Leonor G. Núñez, Salud, trabajo y prostitución en Foro Internacional de Mujeres Contra la Corrupción. Buenos Aires (2004).

Libertad Digital S.A. Una experta afirma que España es el país de la UE donde más fácil es prostituirse Libertad Digital S.A. https://www.libertaddigital.com/sociedad/una-experta-afirma-que-espana-es-el-pais-de-la-ue-donde-masfacil-es-prostituirse-1276217684/

Luis Castillo Córdova, Los precedentes vinculantes del Tribunal Constitucional (1.. ed., 2014).

Luz Pacheco-Zerga, Caracteristicas de la irrenunciabilidad de los derechos laborales, Asesoría Laboral, n. ${ }^{\circ}$ 249, 15-25 (2011).

Luz Pacheco-Zerga, El "Derecho a morir" y el "Deber de matar" por respeto a la dignidad humana, Revista de Derecho, n. 8, 45-60 (2007). https://pirhua.udep.edu.pe/handle/11042/2623

Luz Pacheco-Zerga, La dignidad humana en el Derecho del Trabajo. Madrid: Civitas. (2007).

Luz Pacheco-Zerga, Los elementos esenciales del contrato de trabajo, Revista de Derecho, n. ${ }^{\circ} 13,29-54$ (2012).

Luz Pacheco-Zerga, Trabajo y prostitución: la diferencia entre derecho y esclavitud, 9 Soluciones Laborales, n. ${ }^{\circ} 108$, 104-114 (2016).https://pirhua.udep.edu.pe/bitstream/handle/11042/3866/Trabajo_prostitucion_diferencia _entre_derecho_esclavitud.pdf?sequence=1\&isAllowed $=\mathrm{y}$

Manuel Alonso Olea, De la servidumbre al contrato de trabajo (2.. ed., Tecnos, 1987).

Manuel Alonso Olea, De la servidumbre al contrato de trabajo, Estudios Jurídicos (Tecnos, 1979).

Manuel Alonso Olea, Derecho del Trabajo (26 ed., Thomson \& Civitas, 2006).

Manuel Alonso Olea, Introducción al Derecho del Trabajo (6.. ed., Civitas, 2002).

Manuel Alonso Olea, Las raices del contrato de trabajo, Anales de la Real Academia de Ciencias Morales y Políticas, n. ${ }^{\circ} 21,397-416(1989)$.

Margarita Isabel Ramos Quintana, Irrenunciabilidad de derechos, en Enciclopedia Laboral Básica Alfredo Montoya Melgar, 802-804 (Universidad Complutense de Madrid, Universidad Rey Juan Carlos \& Thomson Reuteres, 2009).

Maria das Neves Rodríguez De Aráujo, Prostitución: ¿trabajo sexual o esclavitud sexual?, en Prostitución: ¿trabajo o esclavitud sexual?, 31-44 (CLADEM, 2003).

Misael Tirado Acero, El debate entre prostitución y trabajo sexual: una mirada desde lo socio-jurídico y la política pública, 6 Revista de Relaciones Internacionales, Estrategia y Seguridad, n. ${ }^{\circ}$ 1, 127-148 (2011).

Oficina de las Naciones Unidas Contra la Droga y el Delito (UNODC), Informe mundial sobre la trata de personas. Resumen ejecutivo, 2014, punto 2. https://www.unodc.org/documents/data-and-analysis/glotip/GLOTIP14 _ExSum_spanish.pdf

Ordenanza 479-CDLO [Consejo Muncipal de Los Olivos]. Ordenanza que prohíbe el ejercicio de la prostitución en todas sus formas en la jurisdicción del distrito. 27 de junio de 2018 (Perú).

Organización Internacional del Trabajo (OIT). Trabajo decente (s. f.). http://www.ilo.org/global/topics/decent-wo $\mathrm{rk} / \mathrm{lang}$--es/index.htm

Parlamento Europeo, Comisión de Derechos de la Mujer e Igualdad de Género. Informe sobre explotación sexual y prostitución y su impacto en la igualdad de género (2013/2103(INI)). Ginebra (2014). https://www.europarl. europa.eu/doceo/document/A-7-2014-0071_ES.html?redirect 
Pedro Brufao Curiel, Prostitución y políticas públicas: entre la reglamentación, la legalización y la abolición (Estudios de Progreso, 2008). https://www.fundacionalternativas.org/public/storage/estudios_documentos_archivos/x mlimport-jPZHqj.pdf

Pedro Serna Bermúdez, El derecho a la vida en el horizonte cultural europeo de fin de siglo, en El derecho a la vida, 23-80 (C.I. Massini \& P. Serna eds., EUNSA, 1998). https://www.corteidh.or.cr/tablas/31473.pdf

Programa de las Naciones Unidas para el Desarrollo (PDNU), Informe sobre Desarrollo Humano 2015: Trabajo al servicio del desarrollo humano (2015). http://hdr.undp.org/sites/default/files/2015_human_development_re port_overview___es.pdf

Rafael Poch, Francia se suma a la penalización de la prostitución con multas al cliente, La Vanguardia (7 de abril, 2016). https://www.lavanguardia.com/internacional/20160407/40943791236/francia-suma-penalizacion-pr ostitucion-multas-cliente.html

Real Academia Española (RAE). Diccionario de la Real Academia Española (2016).

Riccardo Guastini, Antinomia y lagunas, Jurídica. Anuario del Departamento de Derecho de la Universidad Iberoamericana, n. ${ }^{\circ}$ 29, 437-450 (1999). http://historico.juridicas.unam.mx/publica/librev/rev/jurid/cont/29 /cnt/cnt22.pdf

Robert Alexy, Teoría de los derechos fundamentales (Centro de Estudios Constitucionales, 1993).

Robert Spaemann, Sobre el concepto de dignidad humana, en Límites. Acerca de la dimensión ética del actuar, 105-118 (EIUNSA, 2003).

Rosalina Ochoa Díaz \& Amanda C. Muñoz Moreno, La prostitución: ¿un trabajo o una forma de explotación?, en Prostitución: ¿̨trabajo o esclavitud sexual?, 24-30 (CLADEM, 2003).

Sara Torres, Palabras cruzadas, en Prostitución: ¿trabajo o esclavitud sexual?, 11-23 (CLADEM, 2003).

Sarah Bott, Alessandra Guedes, Mary Goowin \& Jennifer Adams Mendoza, Violencia contra las mujeres en América Latina y el Caribe: Análisis comparativo de datos poblacionales de 12 países (Organización Panamericana de la Salud y Centros para el Control y la Prevención de Enfermedades de los Estados Unidos, 2014).

Sentencia del caso LAIS vs. Bar Discoteca PANDEMO (propiedad de Sr. ZOTO), No. T-629-10. Acción de amparo de derechos fundamentales. Corte Constitucional de Colombia. (2010).

Sentencia del caso Lizana Puelles vs. Jurado Nacional de Elecciones, No. 5854-2005-PA/TC. Acción de Agravio Constitucional. Tribunal Constitucional del Perú. (2005)

Sentencia del caso Salazar Yarlenque vs. Municipalidad de Surquillo No. 3741-2004-AA/TC. Acción de amparo de derechos fundamentales. Tribunal Constitucional del Perú. (2005).

The Economist, A giant Teutonic brothel. Prostitution in Germany (2013). https://www.economist.com/europe/201 3/11/16/a-giant-teutonic-brothel

Thomas Escritt, Es oficial: drogas y prostitución impulsan economia holandesa, Reuters (25 de junio, 2014). http://lta.r euters.com/article/worldNews/idLTAKBN0F020X20140625

Tomás Melendo Granados, La dignidad del trabajo (Rialp, 1992).

Zenit Staff, De la prostitución a la conversión: el encuentro de Linda con el Papa, ZENIT (23 de septiembre, 2004). htt ps://es.zenit.org/2004/09/23/de-la-prostitucion-a-la-conversion-el-encuentro-de-linda-con-el-papa/

\section{Notas}

* Artículo de investigación

1 Se puede revisar en http://www.comunidadandina.org/StaticFiles/DocOf/DEC545.pdf

2 Cfr. Sentencias de la Corte Constitucional de Colombia T-629-10 y T-594-16. La Sentencia T-736/15 se basa en los mismos argumentos de la T-629-10, por lo que no es materia de este análisis. La Sentencia T-073/17, que también se pronuncia sobre la prostitución, fue declarada nula mediante Auto 449 de fecha 30 de agosto de 2017 por diversos motivos. La Sentencia SU-062 de 2019 se pronunció sobre la violación del debido proceso administrativo al cerrar la policía un establecimiento dedicado a la 
prostitución, por estar ubicado en una zona no apta para su ejercicio, centra el análisis en las leyes que regulan el uso del suelo. Esta cuestión no tiene relevancia en el Perú, donde es posible prohibir el ejercicio de la prostitución mediante una Ordenanza Municipal, en toda la jurisdicción de un Municipio, tal como ha ocurrido en el distrito de Los Olivos: por esta razón no se incluye esta sentencia en la presente investigación. Ver Ordenanza 479-CDLO [Consejo Municipal de Los Olivos]. Ordenanza que prohíbe el ejercicio de la prostitución en todas sus formas en la jurisdicción del distrito. 27 de junio de 2018 (Perú).

3 Cfr. Constitución de Perú, artículos 201y 202. Código Procesal Constitucional del Perú, artículo 24 . El paralelo lo encontramos en los artículos 241 y 243 de la Constitución de Colombia.

4 Ver Riccardo Guastini, Antinomia y lagunas, Jurídica. Anuario del Departamento de Derecho de la Universidad Iberoamericana, n. ${ }^{\circ}$ 29, 437-450 (1999); Luis Castillo Córdova, Los precedentes vinculantes del Tribunal Constitucional, 17 (1.a ed., 2014).

5 Sobre las normas directamente estatuidas y las adscritas al texto constitucional, ver Robert Alexy, Teoría de los derechos fundamentales, 63-73 (Centro de Estudios Constitucionales, 1993).

6 La Constitución debe interpretarse como un «todo» armónico y sistemático así lo ha recordado el Tribunal Constitucional en una de sus sentencias: "Reconocida la naturaleza jurídica de la Constitución del Estado, debe reconocerse también la posibilidad de que sea objeto de interpretación. No obstante, la particular estructura normativa de sus disposiciones que, a diferencia de la gran mayoría de las leyes, no responden en su aplicación a la lógica subsuntiva (supuesto normativo -subsunción del hecho consecuencia), exige que los métodos de interpretación constitucional no se agoten en aquellos criterios clásicos de interpretación normativa (literal, teleológico, sistemático e histórico), sino que abarquen, entre otros elementos, una serie de principios que informan la labor hermenéutica del juez constitucional. Tales principios son: a) El principio de unidad de la Constitución: Conforme al cual la interpretación de la Constitución debe estar orientada a considerarla como un 'todo' armónico y sistemático, a partir del cual se organiza el sistema jurídico en su conjunto". (Las cursivas no son del original) Sentencia del caso Lizana Puelles vs. Jurado Nacional de Elecciones, No. 5854-2005-PA/TC. Acción de Agravio Constitucional. Tribunal Constitucional. (2005), fundamento jurídico $12 \mathrm{a}$.

7 "La defensa de la persona humana y el respeto de su dignidad son el fin supremo de la sociedad y del Estado". Constitución Política del Perú [Const]. Art. 1.7 de julio de 1993 (Perú).

8 "Colombia es un Estado social de derecho, organizado en forma de República unitaria, descentralizada, con autonomía de sus entidades territoriales, democrática, participativa y pluralista, fundada en el respeto de la dignidad humana, en el trabajo y la solidaridad de las personas que la integran y en la prevalencia del interés general". Constitución Política de Colombia [Const]. Art. 1.7 de julio de 1991 (Colombia).

9 Un estudio detallado de esta cuestión se puede ver en Luis Castillo Córdova, Los precedentes vinculantes del Tribunal Constitucional, 15-30 (1.a ed., 2014). El autor ha preferido el término "adscriptas", que sustituyo por "adscritas", ya que tienen el mismo significado.

10 Íd., 20-22.

11 La doctrina constitucional distingue diversos tipos de sentencias que han surgido como consecuencia de su labor indirectamente legislativa, por su condición de más alto intérprete de la Constitución. Sobre los límites de este tipo de sentencias y las demás clasificaciones realizadas por la doctrina jurídica ver Carlos Hakansson Nieto, Curso de Derecho Constitucional, 55-77 (Palestra, 2009).

12 Ver Sentencia del caso Salazar Yarlenque vs. Municipalidad de Surquillo No. 3741-2004-AA/TC. Acción de amparo de derechos fundamentales. Tribunal Constitucional del Perú. (2005).

13 "Las sentencias del Tribunal Constitucional que adquieren la autoridad de cosa juzgada constituyen precedente vinculante cuando así lo exprese la sentencia, precisando el extremo de su efecto normativo. Cuando el Tribunal Constitucional resuelva apartándose del precedente, debe expresar los fundamentos de hecho y de derecho que sustentan la sentencia y las razones por las cuales se aparta del precedente". Código Procesal Constitucional, art. VII.

14 "Por otro lado, con objeto de conferir mayor predecibilidad a la justicia constitucional, el legislador del Código Procesal Constitucional también ha introducido la técnica del precedente, en su artículo VII del título preliminar, al establecer que 'Las sentencias del Tribunal Constitucional que adquieren la autoridad de cosa juzgada constituyen precedente vinculante cuando así lo expresa la sentencia, precisando el extremo de su efecto normativo (...). De este modo, si bien tanto la jurisprudencia como el precedente constitucional tienen en común la característica de su efecto vinculante, en el sentido de que ninguna autoridad, 
funcionario o particular puede resistirse a su cumplimiento obligatorio, el Tribunal, a través del precedente constitucional, ejerce un poder normativo general, trayendo una norma a partir de un caso concreto". Sentencia del caso Salazar Yarlenque vs. Municipalidad de Surquillo No. 3741-2004-AA/TC. Acción de amparo de derechos fundamentales. Tribunal Constitucional del Perú. (2005).

15 Ver Luis Castillo Córdova, Los precedentes vinculantes del Tribunal Constitucional, 57 (1.a ed., 2014).

16 Sobre esta cuestión ver la falsa antinomia creada por el TC en el fundamento jurídico 25. b. del Expediente n. ${ }^{\circ}$ 333-2006$\mathrm{PA} / \mathrm{TC}$ con relación al supuesto derecho de reingreso a la carrera judicial de los magistrados no ratificados por el Consejo Nacional de la Magistratura, 285-300

17 Íd., 26-31.

18 Exp. n. ${ }^{\circ}$ 4853-2004_PA/TC, fundamento jurídico 16.

19 Constitución del Perú, artículo $22^{\circ}$. El trabajo es un deber y un derecho. Es base del bienestar social y un medio de realización de la persona. Constitución de Colombia, artículo 25. El trabajo es un derecho y una obligación social y goza, en todas sus modalidades, de la especial protección del Estado. Toda persona tiene derecho a un trabajo en condiciones dignas y justas.

20 Constitución de Colombia, artículo 26.

21 Constitución del Perú, artículo 2.15.

22 Constitución del Perú, artículo 2.24 b) y artículo 17 de la Constitución de Colombia.

23 Constitución de Colombia, artículo 23.

24 Constitución de Colombia, artículo 25. El Código Sustantivo de Trabajo, especifica que la subordinación propia del contrato de trabajo no puede afectar "el honor, la dignidad y los derechos mínimos del trabajador en concordancia con los tratados o convenios internacionales que sobre derechos humanos relativos a la materia obliguen al país" (artículo 25).

25 Programa de las Naciones Unidas para el Desarrollo (PDNU), Informe sobre Desarrollo Humano 2015: Trabajo al servicio del desarrollo humano (2015) recogido en Luz Pacheco-Zerga, Trabajo y prostitución: la diferencia entre derecho y esclavitud, 9 Soluciones Laborales, n. ${ }^{\circ}$ 108, 104-114 (2016).

26 Íd., iii y iv

27 Constitución del Perú, artículo 22.

28 Esta es la doctrina común del derecho iberoamericano. En España, ver por todos, Alfredo Montoya Melgar, Derecho del Trabajo, 303-310 (Tecnos, 2014). En Colombia, la Sentencia T-629-10, en particular los fundamentos 79-91. En Perú, se puede revisar lo expresado en Luz Pacheco-Zerga, Los elementos esenciales del contrato de trabajo, Revista de Derecho, n. ${ }^{\circ}$ 13, 29-54 (2012).

29 En cuanto que existe una íntima trabazón entre el servicio prestado y la persona del trabajador. Cfr. por todos Manuel Alonso Olea, De la servidumbre al contrato de trabajo, Estudios Jurídicos, 54 (Tecnos, 1979).

30 Programa de las Naciones Unidas para el Desarrollo (PDNU), Informe sobre Desarrollo Humano 2015: Trabajo al servicio del desarrollo humano, 1 (2015).

31 Íd., 6.

32 Sobre la irrenunciabilidad de derechos laborales remito a lo expresado en Luz Pacheco Zerga, Características de la irrenunciabilidad de los derechos laborales, Asesoría Laboral n. 249, 15-25 (2011).

33 Luz Pacheco-Zerga, Trabajo y prostitución: la diferencia entre derecho y esclavitud, op. cit.

34 Margarita Isabel Ramos Quintana, Irrenunciabilidad de derechos, en Enciclopedia Laboral Básica Alfredo Montoya Melgar, 802 (Universidad Complutense de Madrid, Universidad Rey Juan Carlos \& Thomson Reuteres, 2009).

35 Ver Manuel Alonso Olea, Introducción al Derecho del Trabajo, 77 (6.a ed., Civitas, 2002).

Íd., 78-79. 
37 Íd., 80.

38 Íd., 80.

39 En Perú, ver Ley 27492 y su Reglamento, Decreto Supremo № 010-2003-MIMDES. En Colombia, Ley 1010 de 2006.

40 Ver Manuel Alonso Olea, Las raíces del contrato de trabajo, Anales de la Real Academia de Ciencias Morales y Políticas, n. ○21, 415 (1989).

41 Cfr. Luz Pacheco-Zerga, Trabajo y prostitución: la diferencia entre derecho y esclavitud, op. cit.

42 Íd.

43 Los sistemas de esclavitud se caracterizan por "la negación de la subjetividad, y con ella de la personalidad del esclavo". Manuel Alonso Olea, De la servidumbre al contrato de trabajo, 141 (2.a ed., Tecnos, 1987).

44 Manuel Alonso Olea, Las raíces del contrato de trabajo, op. cit., 416. Es paradigmático el caso del enano de un circo, que era catapultado como si fuera un objeto, para entretenimiento del público y tanto las autoridades francesas como el Comité de Derechos Humanos del Pacto Internacional de Derechos Civiles y Políticos de las Naciones Unidas prohibieron ese número por considerar que era contrario a la dignidad de la persona, aún éste hubiese prestado su consentimiento. Ver Communication No. (CCPR/C/75/D/854/1999) [2002] UNHRC 29 (26 July 2002), especialmente ap. 7.4. http://www.worldlii.org/int/cases/U NHRC/2002/29.html

45 Cfr. Código Penal peruano en los artículos 179 a 181 y en el Código Penal colombiano, en los artículos 213 y 214.

46 Real Academia Española (RAE). Diccionario de la Real Academia Española (2016).

47 Un desarrollo más detallado de estas posturas se encuentra en Misael Tirado Acero, El debate entre prostitución y trabajo sexual: una mirada desde lo socio-jurídico y la política pública, 6 Revista de Relaciones Internacionales, Estrategia y Seguridad, n. ${ }^{\circ}$ 1, 127-148 (2011). También puede revisarse Pedro Brufao Curiel, Prostitución y políticas públicas: entre la reglamentación, la legalización y la abolición (Estudios de Progreso, 2008).

48 A la vez, no se puede negar que, desde planteamientos ideológicos, se difumina el perfil humano porque se plantea el ejercicio de la sexualidad sin más límites que el arbitrio del individuo, que no se somete a más ley que a la de su instinto o goce.

49 Luz Pacheco-Zerga, Trabajo y prostitución: la diferencia entre derecho y esclavitud, op. cit.

50 Sarah Bott, Alessandra Guedes, Mary Goowin, Jennifer Adams Mendoza, Violencia contra las mujeres en América Latina y el Caribe: Análisis comparativo de datos poblacionales de 12 países (Organización Panamericana de la Salud y Centros para el Control y la Prevención de Enfermedades de los Estados Unidos, 2014).

51 Rosalina Ochoa Díaz \& Amanda C. Muñoz Moreno, La prostitución: ¿un trabajo o una forma de explotación?, en Prostitución: ¿trabajo o esclavitud sexual?, 25 (CLADEM, 2003).

52 Íd.

53 Real Academia Española (RAE). Diccionario de la Real Academia Española (2016).

54 Cfr. Luz Pacheco-Zerga, Trabajo y prostitución: la diferencia entre derecho y esclavitud, op. cit.

55 Rosalina Ochoa Díaz \& Amanda C. Muñoz Moreno, op. cit., 25. En el mismo sentido, aportando más datos se pronuncia Augusto Medina Otazu, ¿Tienen derechos laborales las trabajadoras sexuales?, Soluciones Laborales, n. ${ }^{\circ} 99,86$ (2016).

56 Cfr. Luz Pacheco-Zerga, Trabajo y prostitución: la diferencia entre derecho y esclavitud, op. cit.

57 Ver Exp. 4826-2004-AA/TC, fundamento jurídico 5. Esta potestad de regulación se aprecia, por ejemplo, en la Ordenanza $\mathrm{N}^{\circ}$ 384-MSI, que señala como conducta prohibida la siguiente: "8.52) Ofrecer, solicitar, negociar o aceptar, directa o indirectamente, servicios sexuales retribuidos en el espacio público, además conductas que faciliten o vayan encaminadas a promover la prostitución, como transportar, situar en la vía pública, recaudar dinero, imponer condiciones, vigilar la actividad de aquellas personas que la ejerzan". Establece multas para quienes ejercen o soliciten el ejercicio de la prostitución en la vida pública. Es importante advertir que en el año 2019 el Tribunal Constitucional amparó una demanda por vulneración del derecho de defensa de una mujer extranjera, que se dedicaba a la prostitución y no contaba con contrato de trabajo válido ni medios económicos para vivir en el país. La 
vulneración consistió en no permitirle contratar un abogado para defender su derecho de permanencia en el país. El Tribunal no se pronunció sobre la legitimidad de dicho oficio, salvo un voto singular, que replicó los fundamentos de las sentencias de la Corte Constitucional de Colombia, materia de la presente investigación. Cfr. Exp. n. ${ }^{\circ}$ 04729-2W 5-PHC/TC.

58 Cfr. Sentencia T-629-10, en particular, los fundamentos jurídicos del 69 al 92 y la Sentencia T-594-16, que reafirma esta interpretación.

59 Cfr. "Es decir que, no obstante, el conflicto axiológico que plantea, la prostitución existe y sobre todo puede existir (...)". Sentencia T-629-10, fundamento jurídico 100. "Quiere ello decir que la prostitución, como ocurre con otras actividades poco edificantes pero toleradas por el Derecho, puede ser una manifestación de la libre iniciativa y actividad económica (...)”. Fundamento jurídico 104.

60 Ver los estudios de la Organización Mundial de la Salud, según los cuales su situación impide que logren el mayor grado de salud física y mental. Los de la Organización Panamericana de la Salud demuestran que, entre las secuelas físicas y psicológicas que presentan, pueden mencionarse hematomas, huesos rotos, heridas en la cabeza, heridas de arma blanca, lesiones múltiples, pérdida de dentadura. Ver Revista Mujer y Salud. Red de Salud de las Mujeres Latinoamericanas y del Caribe 2-2003. La Morada, Chile, citado por Sara Torres, Palabras cruzadas, en Prostitución: ¿trabajo o esclavitud sexual?, 11-23 (CLADEM, 2003).

61 Sentencia T-629-10, fundamento jurídico 95.

62 Íd., fundamento jurídico 112.

63 Íd., fundamento jurídico 114.

64 Íd., fundamento jurídico 113

65 Íd.

66 Íd., fundamento jurídico 115.

67 Inclusive quienes abogan por su total legalización, reconocen los abusos a los que están sometidas: "a caprichos, depravaciones y desviaciones de los clientes" soportar "el mal carácter de los clientes y los atropellos de autoridades"; ingerir "bebidas alcohólicas para soportar los malos tratos de los clientes"; ante "embarazos no deseados, los abortos son frecuentes (...) y (...) una autoestima baja”. Juan Carlos Romi, La prostitución: enfoque psiquiátrico, sexológico y médico-legal, 13. Alemeon, Revista Argentina de Clínica Neuropsiquiátrica, n. ${ }^{\circ}$, 5-28 (2006).

68 Sarah Bott, Alessandra Guedes, Mary Goowin \& Jennifer Adams Mendoza, op. cit.

69 Ver Parlamento Europeo, Comisión de Derechos de la Mujer e Igualdad de Género. Informe sobre explotación sexual y prostitución y su impacto en la igualdad de género (2013/2103(INI)). Ginebra (2014).

70 Íd.

71 Íd.

72 Íd. La vinculación entre la falta de oportunidades laborales, la trata y la prostitución es cada vez más evidente. Así, por ejemplo, en Francia en los años noventa, el 10\% de las personas que se dedicaban a la prostitución eran extranjeras y en el 2000 eran más del 90\%. Álvaro Rojas, Prostitución: la ley sola no arregla el problema (ACEPRENSA, 2014).

73 Ver Carmen Delgado Álvarez \& Andrea Gutiérrez García, Prostitución: notas para un análisis psicosocial de la coacción al consentimiento, en Igualdad. Retos para el siglo XXI, 37-56 (2012). Ver también José María Sánchez Galera, El oficio menos libre del mundo, ACEPRENSA, (30 de octubre, 2015).

74 Constitución de Colombia, artículo 26.

75 Ver Parlamento Europeo, Comisión de Derechos de la Mujer e Igualdad de Género. Informe sobre explotación sexual y prostitución y su impacto en la igualdad de género (2013/2103(INI)). Ginebra (2014).

76 Maria das Neves Rodríguez De Aráujo, Prostitución: ¿̇trabajo sexual o esclavitud sexual?, en Prostitución: ¿trabajo o esclavitud sexual?, 45 (CLADEM, 2003).

77 Constitución de la Organización Internacional del Trabajo (OIT), Anexo, art. I a). 
79 Inmanuel Kant, Fundamentación de la metafísica de las costumbres, 83-84 (El Cid, 2003).

80 Esta es una de las tres premisas sobre las que se estructura el Derecho Laboral: la distinción entre la persona del trabajador o trabajadora y la de sus servicios. Hemos hecho referencia a este desarrollo en la comprensión del respeto a la dignidad del trabajador/ a, en el apartado "El derecho fundamental al trabajo y su regulación jurídica", ut supra, nota 44.

81 Parlamento Europeo, Comisión de Derechos de la Mujer e Igualdad de Género. Informe sobre explotación sexual y prostitución y su impacto en la igualdad de género (2013/2103(INI)). Ginebra (2014).

82 Cfr. Luz Pacheco-Zerga, Trabajo y prostitución: la diferencia entre derecho y esclavitud, op. cit.

83 Sobre la inexistencia del derecho al suicidio puede revisarse la sentencia del Tribunal Constitucional español 120/90 (RTC 120, 90). Para un estudio de mayor amplitud sobre el denominado derecho al suicidio, remito a Luz Pacheco-Zerga, El "Derecho a morir" y el "Deber de matar" por respeto a la dignidad humana, Revista de Derecho, n. 8, 45-60 (2007).

84 Cfr. Comunicación de la Comisión, de 9 de diciembre de 1998, al Consejo y al Parlamento Europeo sobre nuevas medidas en el ámbito de la lucha contra la trata de mujeres establece las siguientes: "En el plano social, resultan importantes tanto la asistencia social específica para las víctimas (centros de acogida, reinserción) como los controles administrativos más estrictos de las condiciones de trabajo en ciertos sectores de actividad. A largo plazo, la prevención constituye un elemento clave para cambiar la actitud de la sociedad hacia la explotación sexual de las mujeres. Para ello, la Comisión se propone utilizar las políticas y los programas existentes en materia social (INTEGRA), educativa (LEONARDO) y de salud para luchar contra el racismo y promover la igualdad de oportunidades y los derechos humanos. El programa DAPHNE se encuadra también en este enfoque, apoyando a las ONG que actúan sobre el terreno". Respecto a los daños que produce el ejercicio de ese oficio los estudios de la Organización Mundial de la Salud señalan que su situación impide que logren el mayor grado de salud física y mental. Los de la Organización Panamericana de la Salud demuestran que, entre las secuelas físicas y psicológicas que presentan, pueden mencionarse hematomas, huesos rotos, heridas en la cabeza, heridas de arma blanca, lesiones múltiples, pérdida de dentadura. Sara Torres, op. cit., 21. En similar sentido se pronuncia el informe del Parlamento Europeo, Comisión de Derechos de la Mujer e Igualdad de Género. Informe sobre explotación sexual y prostitución y su impacto en la igualdad de género (2013/2103(INI)). Ginebra (2014). Estos datos fueron recogidos previamente en Luz Pacheco-Zerga, Trabajo y prostitución: la diferencia entre derecho y esclavitud, op. cit.

85 Libertad, Digital S.A., Una experta afirma que España es el país de la UE donde más fácil es prostituirse (Libertad Digital S.A., 2004 fecha acceso 2020]). https://www.libertaddigital.com/sociedad/una-experta-afirma-que-espana-es-el-pais-de-la-ue-dondemas-facil-es-prostituirse-1276217684/. Para un estudio en profundidad de este tema remito a lo publicado en Luz Pacheco-Zerga, La aplicación del Derecho del Trabajo, Jurisprudencia TSJ, AP y otros Tribunales, 2004, 11-27.

86 Pedro Brufao Curiel, op. cit.

87 Marina Dorado. Las sorprendentes cifras de la prostitución en España. Mujeres a Seguir. Ubicado en MAS. Mujeres a seguir. [citado el 5 noviembre 2020) https://www.mujeresaseguir.com/social/noticia/1120252048615/sorprendentes-cifras-de-prostit ucion-espana.1.html (2019).

88 Oficina de las Naciones Unidas Contra la Droga y el Delito (UNODC), Informe mundial sobre la trata de personas. Resumen ejecutivo, 2014, punto 2 .

89 Los estudios que se citan a continuación se han extraído de mi segunda aproximación a la calificación de trabajo, que se hizo en el Perú del oficio de la prostitución y que están recogidos en la obra ya citada Trabajo y prostitución: la diferencia entre derecho y esclavitud, op. cit.

90 Sara Torres, op. cit., 14.

91 Leonor G. Núñez, Salud, trabajo y prostitución en Foro Internacional de Mujeres Contra la Corrupción. Buenos Aires (2004).

92 Íd. 14-15 "El famoso distrito rojo y los 'coffee shops' holandeses que venden sexo y drogas contribuyen con 2.500 millones de euros por año a la economía nacional, o algo más del consumo de queso del país, dijeron las autoridades holandesas. Cálculos oficiales difundidos el miércoles bajo nuevas guías europeas mostraron que la industria representaba alrededor del 0,4 por ciento del producto interno bruto (PIB)". Thomas Escritt, Es oficial: drogas y prostitución impulsan economía holandesa, Reuters (25 de junio, 2014). 
93 Cecilia Lipsyc, Mujeres en situación de prostitución: ¿esclavitud sexual o trabajo sexual?, en Prostitución: ¿trabajo o esclavitud?, 59 (CLADEM, 2003).

94 Íd., 60.

95 Íd., 60.

96 En Argentina se demostró que las ONG -ONUSIDA y LUSIDA-implementaron "planes de prevención de VIH-SIDA, convocando a personas en prostitución como promotoras para llevarlos a cabo siempre que éstas se agrupasen como "trabajadoras sexuales" o "trabajadores del sexo". Cfr. Sara Torres, op. cit., 15. Sería interesante un estudio de campo en este sentido en Perú y en Colombia para descubrir lo que hay detrás de las asociaciones que pretenden representar a todas las personas que se dedican a este oficio.

97 Artículo $1^{\circ}$ de la Constitución del Perú.

98 Artículo $1^{\circ}$ de la Constitución de Colombia.

99 Cfr. Luz Pacheco Zerga. La dignidad humana en el Derecho del Trabajo. Madrid: Civitas, 401-407; 409-412; 415-417. (2007).

100 Ver Antonio Millán Puelles, Sobre el hombre y la sociedad, 98 (Rialp, 1976).

101 Íd., 97.

102 "Axiomata, dignitates, son en el orden lógico — no en el psicológico— las verdades objetivamente irreductibles, las que valen en sí, sin posibilidad de mediación”. Íd.

103 Robert Spaemann, Sobre el concepto de dignidad humana, en Límites. Acerca de la dimensión ética del actuar, 107 (EIUNSA, 2003).

104 El ser humano al satisfacer sus necesidades, como puede ser la de ingerir alimentos o cubrirse ante las inclemencias del tiempo, podría hacerlo al modo de los animales, pero la razón le indica que no debe encerrarse en su propia necesidad, sino que debe conservar la actitud de diálogo y respeto a los demás, precisamente por la interdependencia humana. De ese modo, cuando satisface sus necesidades crea cultura.

105 Ana Marta González, La dignidad de la persona, presupuesto de la investigación científica, en Biotecnología, Dignidad y Derecho: bases para un diálogo, 30 (EUNSA, 2004).

106 "Caracterizar la dignidad humana en términos de autonomía no pasa de ser una verdad o un error filosóficos si no pretende constituirse, a la vez, en criterio para determinar quién es un ser humano y quién no lo es, es decir, en criterio para el reconocimiento de la humanidad y de los derechos". Pedro Serna Bermúdez, El derecho a la vida en el horizonte cultural europeo de fin de siglo, en El derecho a la vida, 44 (C.I. Massini \& P. Serna eds., EUNSA, 1998).

107 El Preámbulo de la Declaración Universal de los Derechos del Hombre (10.XII.1948) reafirmó que "la libertad, la justicia y la paz en el mundo tienen por base el reconocimiento de la dignidad intrínseca y de los derechos iguales e inalienables de todos los miembros de la familia humana". (El subrayado no es del original). Y declara expresamente en su primer artículo que "todos los seres humanos nacen libres e iguales en dignidad y derechos y, dotados como están de razón y conciencia, deben comportarse fraternalmente los unos con los otros".

108 Hesiodo, Teogonía; Trabajos y días; Escudo; Certamen (Adelaida Martín Sánchez y María Ángeles Martín Sánchez eds., Alianza Editorial, 2000).

109 Robert Spaemann, op. cit., 110.

110 "Históricamente, la garantía de la dignidad humana se encuentra estrechamente ligada al cristianismo. Su fundamento radica en que el hombre ha sido creado a imagen y semejanza de Dios". Ernesto Benda, Dignidad humana y derechos de la personalidad, en Manual de Derecho Constitucional, 117 (Ernesto Benda et al. eds., Marcial Pons, 2001).

111 Josef Pieper, ¿Qué significa "sagrado"? Un intento de clarificación, 21 (Rialp, 1990). En la fe cristiana reconocer "la imagen de Dios" en los demás exige promover una vida acorde con esa dignidad, que sólo se consigue en base al "respeto de los derechos y de las necesidades de todos, especialmente de los pobres, los marginados y los indefensos". Benedicto XVI. Deus caritas est (Palabra, 2006). 
112 "La moralidad es aquella condición bajo la cual un ser racional puede ser un fin en sí mismo, puesto que sólo por ella es posible ser miembro legislador en un reino de los fines. Así pues, la moralidad y la humanidad en cuanto que es capaz de moralidad son lo único que posee dignidad". Inmanuel Kant, op. cit., 86.

113 Cfr. Inmanuel Kant, op. cit., 86. A la vez, si bien es cierto que la persona no se puede reducir a un medio para otros fines, sería inexacto afirmar que esta característica la encierre en sí misma, transformando a cada individuo "en un fin en sí mismo” porque “la condición de ser relacional es inherente a la persona. El ser humano ha sido creado con una tendencia primaria hacia el amor, hacia la relación con el otro. No es un ser autárquico, cerrado en sí mismo, una isla en la existencia, sino, por su naturaleza, es relación. Sin esa relación, en ausencia de relación, se destruiría a sí mismo". Joseph Ratzinger, Dios y el mundo. Creer y vivir en nuestra época. Una conversación con Peter Seewald, 104 (Galaxia Gutenberg, 2005).

114 Cfr. Inmanuel Kant, op. cit., 23.

115 Se desconocen los "absolutos morales", que son aquellos que permiten identificar "acciones incorrectas, no acciones correctas", es decir, aquellas "normas negativas, que resultan válidas siempre y en toda ocasión”. John Finnis, Absolutos morales: tradición, revisión y verdad (Trad. Juan José García Norro). Barcelona: EIUNSA. (1992).

116 Sentencia T-629-10, fundamento jurídico 115.

117 Corte Constitucional de Colombia, T-629-10, fundamento jurídico 95 (las cursivas no son del original).

118 Andrés Ollero, Derechos humanos y metodología jurídica, 152 (Centro de Estudios Constitucionales, 1989).

119 Siguiendo a Finnis, podemos decir que son seis: “1) vida (su mantenimiento y transmisión, salud y seguridad); 2) conocimiento y experiencia estética; 3) excelencia en el trabajo y en el juego; 4) amistad, paz y fraternidad; 5) paz interior, autointegración y autenticidad; y 6) armonía con los más amplios ámbitos de la realidad, en especial con Dios y con el entorno natural”. FINNIS, J.; BOYLE, J. y GRISEZ, G. Nuclear Deterrence, Morality and Realism, Oxford, Clarendon Press, 1987, 278-281, citado por Carlos Ignacio Massini, El derecho a la vida en la sistemática de los derechos humanos, en El derecho a la vida, 191 (C.I. Massini \& P. Serna eds., EUNSA, 1998).

120 Íd.

121 Pedro Serna Bermúdez, op. cit., 42.

122 Ver Jesús Ballesteros, El individualismo como obstáculo a la universalidad de los derechos humanos, Revista Persona y Derecho, n. ${ }^{\circ} 41,15-16$ (1999).

123 Para estos autores, los derechos son siempre "mis derechos", por tanto, los demás "no deben, pero yo sí puedo violar mis propios derechos, por ejemplo, enajenado mi libertad, tal como postula Nozikc, al considerar lícita la esclavitud por voluntad propia”. Íd.18.

124 "Aquello que tiene precio puede ser sustituido por algo equivalente; en cambio, lo que se halla por encima de todo precio y, por tanto, no admite nada equivalente, eso tiene una dignidad”. Inmanuel Kant, La metafísica de las costumbres, 439 (Adela Cortina Orts y Jesús Conill Sancho trads,. Madrid: Altaya, 1989). Sobre desarrollo de las ideas en torno a la dignidad del trabajador, ver el estudio realizado por Manuel Alonso Olea, De la servidumbre al contrato de trabajo, Estudios Jurídicos (Tecnos, 1979).

125 Transcribo el perfil psicológico de las personas que se prostituyen, según un médico, que aboga por la legalización de la prostitución y lleva treinta y seis años analizando a este colectivo: "Dentro de los rasgos más salientes del perfil de una prostituta se observan: cierta limitación intelectual, inestabilidad emocional, inconstancia y abulia laboral. Proclividad al desorden financiero, el derroche y al lujo ostentoso. Conductas irreflexivas superficiales y transgresoras. Tendencia a la diversión y aturdimiento en una supuesta vida dedicada a pasarla bien, que contrasta con el pesimismo y desesperanza con que vivencia su futuro. Falta de discernimiento entre lo verdadero y lo falso. Espíritu aventurero irreflexivo sin medir las consecuencias. Cierta ingenuidad y credulidad en las promesas de terceros". Juan Carlos Romi, op. cit.

126 No se puede desconocer la influencia que la religión tiene en la vida social. "La religión es, sin duda, el aspecto más importante de una cultura determinada. Es precisamente la religión la que suele dar coherencia y unidad a una cultura y a una organización social. Hay de hecho una relación dialéctica entre cultura y religión, dado que ambas se influyen mutuamente tanto a niveles superficiales como a niveles profundos". José Morales, Teología de las religiones, 48 (Rialp, 2001).

127 Ver un amplio estudio de esta cuestión en Andrés Ollero, Democracia y convicciones en una sociedad plural (Navarra Gráfica Ediciones, 2001). 
128 "La moral pretende hacer al hombre lo más perfecto posible; por tanto, es maximalista en sus exigencias. El derecho se conforma con que los hombres convivan humanamente”. Andrés Ollero, Derecho a la verdad: valores para una sociedad pluralista, 58 (EUNSA, 2005).

129 En España este fenómeno tiene más de una década como puede apreciarse en las sentencias de los tribunales de justicia de 20 noviembre 2001 (TJC 2001, 314) y SAN 104/2003 (Sala de lo Social), (AS 2003\3692). En Colombia son emblemáticas las sentencias de la Corte Constitucional de los Expedientes T 629-10 y T-594-16, materia de esta investigación.

130 Cfr. artículos 2.24 h) de la del Perú y 12 de Colombia.

131 Sigue siendo actual el testimonio una exprostituta australiana que está trabajando en su país de origen, en la rehabilitación de mujeres dedicadas a la prostitución. Ella declaró a la opinión pública que muchas de esas jóvenes atienden de ocho a quince "clientes" cada día y por las drogas y la violencia que existe en la sociedad, terminan sin prendas y sin dientes, que les han sido arrancados a golpes por los "clientes". Para más información ver Zenit Staff, De la prostitución a la conversión: el encuentro de Linda con el Papa, ZENIT (23 de septiembre, 2004). Se comprueba la actualidad de ese testimonio al leer el de Brenda MyersPowell, Violada, baleada, apuñalada: “Sobreviví 25 años de prostitución”, Mundo (2015).

132 Cfr. Rafael Poch, Francia se suma a la penalización de la prostitución con multas al cliente, La Vanguardia (7 de abril, 2016). https://www.lavanguardia.com/internacional/20160407/40943791236/francia-suma-penalizacion-prostitucion-multas -cliente.html

133 Cfr. Íd.

134 Este dato fue recogido en The Economist, A giant Teutonic brothel. Prostitution in Germany (2013). Además, ha sido confirmado por el Parlamento de la Unión Europea en el punto AA del Parlamento Europeo, Comisión de Derechos de la Mujer e Igualdad de Género. Informe sobre explotación sexual y prostitución y su impacto en la igualdad de género (2013/2103(INI)). Ginebra (2014). En un Congreso mundial contra explotación sexual de mujeres y chicas, el Coalition Abolition Prostitution (CAP) realizado en 2019 se ha denunciado el sistema de explotación sexual que implica esta legalización. Cfr. http://www.cap-intern ational.org/es/activity/significant-impact-of-our-3rd-world-congress-in-germany/ Según las estadísticas, en Alemania hay entre doscientas mil y un millón de prostitutas. Cfr. https://www.dw.com/es/alemania-exigen-prohibir-la-prostituci\%C3\%B3n/a-482 04520

135 Íd.

136 Parlamento Europeo, Comisión de Derechos de la Mujer e Igualdad de Género. Informe sobre explotación sexual y prostitución y su impacto en la igualdad de género (2013/2103(INI)). Ginebra (2014).

\section{Licencia Creative Commons CC BY 4.0}

Cómo citar este artículo: Luz Pacheco Zerga, El carácter laboral de la prostitución en la jurisprudencia constitucional peruana y colombiana, 69 Vniversitas (2020). https://doi.org/10.11144/Javeriana.vj69.clpj 